\title{
Ethanol Production in Actinomycetes after Expression of Synthetic adhB and pdc
}

\author{
Uwe Hardter^, Marta Luzhetska^, Sandra Ebeling and Andreas Bechthold*
}

Albert-Ludwigs-Universität, Institut für Pharmazeutische Wissenschaften, Pharmazeutische Biologie und Biotechnologie, Stefan-Meier-Straße 19, 79104 Freiburg, Germany

\begin{abstract}
Streptomyces strains are producing many important secondary metabolites, in many cases used as pharmaceutical drugs. Though the usage of these bacteria for the production of fuel has never been described. We could show, that the expression of two artificial ethanologenic genes of Zymomonas mobilis in different actinomycetes strains resulted in the production of ethanol. The synthetic genes $a d h \mathrm{~B}$ and pdc encoding an alcohol dehydrogenase and a pyruvate decarboxylase, respectively, were expressed in eight different Streptomyces strains. Best production was obtained using Streptomyces coelicolor A3(2) harboring both genes. By variation of the cultivation conditions, the amount of ethanol produced by the strain could be increased up to $2.6 \mathrm{~g} / 1$.
\end{abstract}

Keywords: Ethanol production, Streptomyces, synthetic biology, actinomycetes, alcohol dehydrogenase, pyruvate decarboxylase.

\section{INTRODUCTION}

The introduction of genes into an organism, allowing the development of novel biological functions, is defined as synthetic biology [1]. Important areas for synthetic biology approaches are biomedicine, the synthesis of biopharmaceuticals, the production of chemicals and biomaterials, the environment and energy. Energy sources, which derive in some way from biomass, are gaining great popularity and scientific importance [2]. For example, the world ethanol production increased around threefold in the last ten years from about $30,000 \times 10^{6}$ liter in the year 2000 up to more than $80,000 \times 10^{6}$ liter in 2010 [3]. Ethanol is an important biofuel, which has considerable advantages in terms of sustainability, lower greenhouse gas emissions, and cost reduction opposite to fossil fuels. Bioethanol is mostly produced from corn-starch, especially in the U.S.. Main producers are Zymomonas mobilis, Saccharomyces cerevisiae and engineered Escherichia coli strains [2, 4], producing maximum ethanol amounts between $40-90 \mathrm{~g} / \mathrm{l}$. However, these microorganisms industrially used for large scale production of biofuels, currently are not able to utilize non-edible lignocellulosic feedstock but depend on the fermentable monosaccharide glucose. Thereby, the current biofuel production proves only marginally profitable and is furthermore disputed in ethical regard. Thus, intensive research effort has been employed to realize the use of lignocellulosic feedstock in biofuel production [5]. One approach to reach this goal is to introduce cellulolytic ability into common ethanol producing organisms as described by Linger et al. [7] who success-

\footnotetext{
*Address correspondence to this author at the Albert-Ludwigs-Universität, Institut für Pharmazeutische Wissenschaften, Pharmazeutische Biologie und Biotechnologie, Stefan-Meier-Straße 19, 79104 Freiburg, Germany; Tel: (+49) 761-203-8371; Fax: (+49) 761-203-8383;

E-mail: andreas.bechthold@pharmazie.uni-freiburg.de

${ }^{\wedge}$ Contributed equally
}

fully expressed cellulolytic enzymes from Acidothermus cellulolyticus in Z. mobilis [6, 7]. Another strategy would be to express ethanol generating enzymes in bacteria which are known as cellulose utilizing organisms.

Streptomyces is a genus of the Actinobacteria with more than 500 species. Most of these species are producers of various secondary metabolites which have been developed as pharmaceutical drugs in many cases. In our opinion these bacteria are very valuable organisms for the production of biofuels. They have the capacity to withstand relatively low $\mathrm{pH}$, high temperature, high sugar, salt and ethanol concentrations, as well as various other harsh conditions, which could be used to develop an advanced biocatalyst and improve the commercial competitiveness of fuel ethanol production. In addition, actinomycetes produce a broad range of interesting enzymes which allow the degradation of complex glycans, such as cellulose and hemicellulose. This might help to overcome the current problem of shortage of feedstock supply when starch or sugar is used.

As Streptomyces strains are not known to produce ethanol by nature, introduction of genes allowing the strains to perform an ethanologenic pathway is essential. Application of synthetic biology approaches in actinomycetes is still under development [8]. In this study we describe the application of synthetic biology to Streptomyces. Two synthetic genes were introduced into different Streptomyces strains enabling the strains to produce ethanol.

\section{MATERIALS AND METHODOLOGY}

\section{Strains, Plasmids and Culture Conditions}

Escherichia coli DH5 $\alpha$ and E. coli XL1 blue (Life Technologies, Carlsbad) were used for propagating plasmid clones. Plasmids were passed through E. coli ET12567 (dam-, dcm-, hsds-, $\mathrm{Cm}+$ ) to generate demethylated DNA 
[9]. E. coli ET 12567 carrying the RP4 derivative pUZ8002 was used for intergeneric conjugations from E. Coli to Streptomyces. E. coli strains were grown under standard conditions [10] on Luria-Bertani (LB) medium containing hygromycin $(50 \mu \mathrm{g} / \mathrm{ml})$, apramycin $(50 \mu \mathrm{g} / \mathrm{ml})$, carbenicillin $(50 \mu \mathrm{g} / \mathrm{ml})$ or kanamycin $(30 \mu \mathrm{g} / \mathrm{ml})$ for antibiotic selection as required. Exconjugands were grown on MS agar containing adequate antibiotics for selection.

Production cultures of Streptomyces strains: S. cyanogenus S136 [11], S. sp. Tü 6071[12], S. fradiae Tü 2717 [13], S. cinnamonensis [14] S. collinus [15], S. coelicolor CH999 [16], S. lividans 1326 [17], S. coelicolor M1154 [18] and S. coelicolor A3(2) [17] were grown at $28^{\circ} \mathrm{C}$ in $100 \mathrm{ml}$ of liquid medium. HA medium (yeast extract, $4 \mathrm{~g} / 1$; malt extract, 10g/l; D-glucose, $4 \mathrm{~g} / \mathrm{l} ; \mathrm{CaCl}_{2}, 1 \mathrm{M}$ ), TSB medium (tryptic soy broth, $30 \mathrm{~g} / \mathrm{l}$ ), NL111 medium (Lab lemco meat extract, $20 \mathrm{~g} / \mathrm{l}$; malt extract, $\left.100 \mathrm{~g} / \mathrm{l} ; \mathrm{CaCO}_{3} 10 \mathrm{~g} / \mathrm{l}\right)$, NL 19 medium (D-mannitol, $20 \mathrm{~g} / \mathrm{l}$; soy flour,20g/l) and E1 medium (starch $20 \mathrm{~g} / \mathrm{l}$; D-glucose, $20 \mathrm{~g} / \mathrm{l}$; yeast extract, $2.5 \mathrm{~g} / \mathrm{l}$; pharmamedia cottonseed flour, $3 \mathrm{~g} / 1 ; \mathrm{CaCO}_{3}, 1 \mathrm{~g} / \mathrm{l} ; \mathrm{NaCl}, 2 \mathrm{~g} / 1 ; \mathrm{KHPO}_{4}, 1$ $\mathrm{g} / \mathrm{l} ; \mathrm{MgSO}_{4}, 1 \mathrm{~g} / \mathrm{l}$ ) containing appropriate antibiotics for selection had been tested for best production levels, which could be obtained using NL 111 medium.

For cultivation under "semi-anaerobic" conditions flasks were closed using parafilm.

\section{GENETIC METHODS}

Isolation of plasmid and chromosomal DNA, conjugation and other gene cloning techniques for actinomycetes were performed using protocols that have been described by Kieser et al. [14].

RNA was isolated using the SV Total RNA Isolation System from Promega GmbH, Mannheim, Germany. For RT PCR the QuantiTect Rev. Transcription Kit from Qiagen, Hilden, Germany was used.

The manipulation of E. coli DNA and other standard molecular biology procedures were performed as described previously [10]. Restriction enzymes were purchased from Promega GmbH, Mannheim, Germany.

All products were used according to manufacturers' instructions.

\section{PLASMID CONSTRUCTION}

Assembling of the nucleotide sequence of $a d h \mathrm{~B}$ and $p d c$ according to the actinomycetes codon usage was performed by GenScript Corporation, Piscataway, NJ, USA. Fdh, as well adapted to the actinomycetes codon usage, was purchased from Mr. Gene GmbH, Regensburg, Germany. All three genes were ligated into pUC57, resulting in pUC57$a d h \mathrm{~B}, \mathrm{pUC} 57-p d c$, and pUC57-fdh, respectively. As expression vector, pUWL-H-tnp [19] was used. Gene $a d h \mathrm{~B}$ was cloned into the HindIII and XbaI sites of pUWL-H-tnp, resulting in pUWL-H-adh (tnp gene was removed by this cloning step). For construction of pUWL-H-adh-pdc, pUC-57$p d c$ was restricted by SpeI. The fragment containing $p d c$ was ligated into the $\mathrm{Xba \textrm {I }}$ site of pUWL-H-adh. For coexpression of $a d h \mathrm{~B}, p d c$, and $f d h$, pUWL-H- $a d h-p d c-f d h$ was used. The plasmid was generated by ligation of $f d h$ into pUWL-H-adhpdc using HindIII and ClaI restriction sites.

\section{ETHANOL EXTRACTION AND ANALYSIS}

After 5 days of incubation, cultures were centrifuged. Mycelium was separated from supernatant and dried for 48 hours at $60{ }^{\circ} \mathrm{C}$. Dry weight was measured subsequently. Average mass of mycelium in cultures of $S$. coelicolor A3(2) $\mathrm{x}$ adh-pdc (S. coelicolor A3(2) containing pUWL-H-adhpdc) was $15,4 \mathrm{~g} / 100 \mathrm{ml}$ under aerobic conditions and 15,0 $\mathrm{g} / 100 \mathrm{ml}$ under "semi-anaerobic" conditions. In case of $S$. coelicolor x pUWL-H, we measured $16,8 \mathrm{~g} / 100 \mathrm{ml}$ under aerobic conditions and $15,0 \mathrm{~g} / 100 \mathrm{ml}$ under "semianaerobic" conditions, respectively.

Expression of introduced synthetic genes $a d h \mathrm{~B}$ and $p d c$ was proved by RT PCR following RNA isolation

For ethanol analysis an internal standard $(0.03 \mathrm{ml} \mathrm{1-}$ propanol) was added to $30 \mathrm{ml}$ of the supernatant. Extraction was performed with $10 \mathrm{ml}$ ethyl acetate. After addition of sodium sulphate, samples were analyzed by GC/MS using a HP6890 series GC-system coupled to an Agilent 5973 Network Mass Detector. As column we used a capillary tube (Optima 1), $30 \mathrm{mx} 25 \mathrm{~mm}$, coated with $25 \mu \mathrm{m}$ dimethylsiloxan. As carrier gas, helium was used and the flow was $1 \mathrm{ml} / \mathrm{min}$. The temperature program started at $60^{\circ} \mathrm{C}$ and was held for $2 \mathrm{~min}$, followed by a ramp of $10^{\circ} \mathrm{C} / \mathrm{min}$ to $220^{\circ} \mathrm{C}$, which was held for $10 \mathrm{~min}$. The final temperature of $270^{\circ} \mathrm{C}$ was reached by a second ramp of $55^{\circ} \mathrm{C} / \mathrm{min}$ and was held for $5 \mathrm{~min}$. The injector and detector temperatures were set to $280^{\circ} \mathrm{C}$, the injection volume was $1.0 \mu \mathrm{l}$ and the split was 10:1. Mass spectra were recorded. The acquisition mode was a MID (Multiple Ion Detector) monitoring ions $\mathrm{m} / \mathrm{z} 31$ and 45 for ethanol and 1-propanol (internal standard). Quantification was performed measuring the SIM area of the respective $\mathrm{m} / \mathrm{z} 31$ peak. Calibration of the system was performed using ethanol in a concentration of $0,1 \%$ to $5 \% 0(\mathrm{~V} / \mathrm{V})$ in ethyl acetate.

\section{RESULTS AND DISCUSSION}

Pyruvate is a common intermediate of the primary metabolism of many organisms. Two steps, catalyzed by a pyruvate decarboxylase and an alcohol dehydrogenase, are required to convert pyruvate into ethanol [20]. Streptomyces strains are not known to produce ethanol and the reason for this might be the absence of functional pyruvate decarboxylase and alcohol dehydrogenase genes [21, 22]. In contrast to many other bacteria the DNA of actinomycetes is very GC rich, with a GC content of 70-80\% [17]. Very often AT rich genes cannot be expressed in actinomycetes efficiently, as the supply of tRNAs complementary to rare codons like UUA, UUU or AUA is not guaranteed, resulting in small amounts of protein and/or misincorporated amino acids [23, 24]. In order to coexpress a pyruvate decarboxylase gene (pdc) together with a NADH dependent alcohol dehydrogenase gene (adhB), two artificial GC-rich genes were generated. Pdc and $a d h \mathrm{~B}$, both from Z. mobilis, were used as templates. 204 of 386 codons in adhB and 269 of 569 codons in $p d c$ are considered rare codons as they are found with a frequency of less than $1 \%$ in the $S$. coelicolor A3(2) genome [24]. We adapted these genes to the S. coelicolor codon 
usage, assuring a higher translational efficiency in Streptomycetes as these bacteria prefer $\mathrm{G}$ and $\mathrm{C}$ nucleotides in the wobble position [17]. By substituting 255 nucleotides within 1152 of the whole gene, a synthetic alcohol dehydrogenase gene (adhB) was designed in silico and synthesized by Gene Script Corporation, Piscataway, NJ, USA. For the synthetic pyruvate decarboxylase gene, 385 of $1707 \mathrm{bp}$ were changed. Artificial genes were surrounded by suitable restriction enzyme sites, allowing the construction of pUWL-H-adh-pdc. In this plasmid, expression of both genes is controlled by the strong ermE promoter. pUWL-H-adh-pdc was introduced into S. cyanogenus S136, S. sp. Tü 6071, S. fradiae Tü 2717, S. cinnamonensis, S. collinus, S. coelicolor CH999, S. lividans 1326 and $S$. coelicolor A3(2) by intergeneric conjugation with E. coli harboring this plasmid.

Exconjugands of these strains were cultivated in NL19-, NL111-, E1- und HA medium. After 5 days ethanol production was not detectable in extracts of strains cultivated in NL19- and E1-medium. However, it was detectable in extracts of S. coelicolor A3(2) x adh-pdc $(20 \mathrm{mg} / \mathrm{l})$ cultivated in HA medium and in extracts of S. coelicolor A3(2) x adh-pdc (510 mg/l), S. fradiae Tü 2717 x adh-pdc $(158 \mathrm{mg} / \mathrm{l}), S$. cyanogenus S136 x adh-pdc (64 mg/l), S. coelicolor CH999 $\mathrm{x}$ adh-pdc $(10 \mathrm{mg} / \mathrm{l})$, and S. lividans $1326 \mathrm{x}$ adh-pdc $(2 \mathrm{mg} / \mathrm{l})$ cultivated in NL111 medium. As the most promising results were obtained with S. coelicolor A3(2) x adh-pdc it was subsequently used for further experiments.

We observed that ethanol production could be increased to $1.5 \mathrm{~g} / \mathrm{l}$ when D-glucose in a concentration of $4 \mathrm{~g} / \mathrm{l}$ was added to the medium and when the strain was cultivated for six days. Even more, when the strain was cultivated in a flask which was closed by parafilm to minimize ethanol evaporation and to achieve lower oxygen concentration in cultures ("semi-anaerobic" conditions) ethanol production was at $2.6 \mathrm{~g} / \mathrm{l}$ (Fig. 1). Pyruvate in a concentration of $1 \mathrm{~mol} / \mathrm{l}$ did not influence ethanol formation (data not shown).

The enzyme Fdh from Candida boindinii, a formate dehydrogenase, is influencing the intracellular concentrations of both NADH and NAD ${ }^{+}$[25]. Expression of $f d h$, which was adapted to the $S$. coelicolor codon usage as described for the other two genes, led to a significantly higher ethanol production in E. coli $[25,26]$. In our studies coexpression of $a d h \mathrm{~B}, p d c$ and $f d h$ was performed in S. coelicolor A3(2) and ethanol production after addition of formate in different concentrations was investigated. We could not obtain higher ethanol amounts in any experiment (data not shown).

Also when adhB and pdc were expressed in S. coelicolor M1154, which has been described as suitable producing host for secondary metabolites [18], ethanol production was comparable to the production in S. coelicolor A3(2) x adh-pdc (data not shown).

Metabolic engineering, as well as synthetic biology have been aiming at creating industrial methods for the production of compounds and usually exploit rational model-supported, computed approaches for the design of experiments. This approach has resulted in some very successful industrial projects with some model bacterial systems, in particular $E$. coli and Bacillus subtilis, where normal cellular metabolism may be altered to produce nonnatural metabolites or to shift the balance of synthesis toward a key metabolite of interest leading to novel production systems for vitamins and fine chemicals [1]. While metabolic engineering is widely used for the generation of novel natural products like antibiotics and anticancer drugs, the application of synthetic biology to actinomycetes has not been described very often. In our study we were able to introduce two artificial genes into $S$. coelicolor A 3(2), allowing the strain to produce ethanol up

\section{Ethanol production of S. coelicolor A3(2) strains}

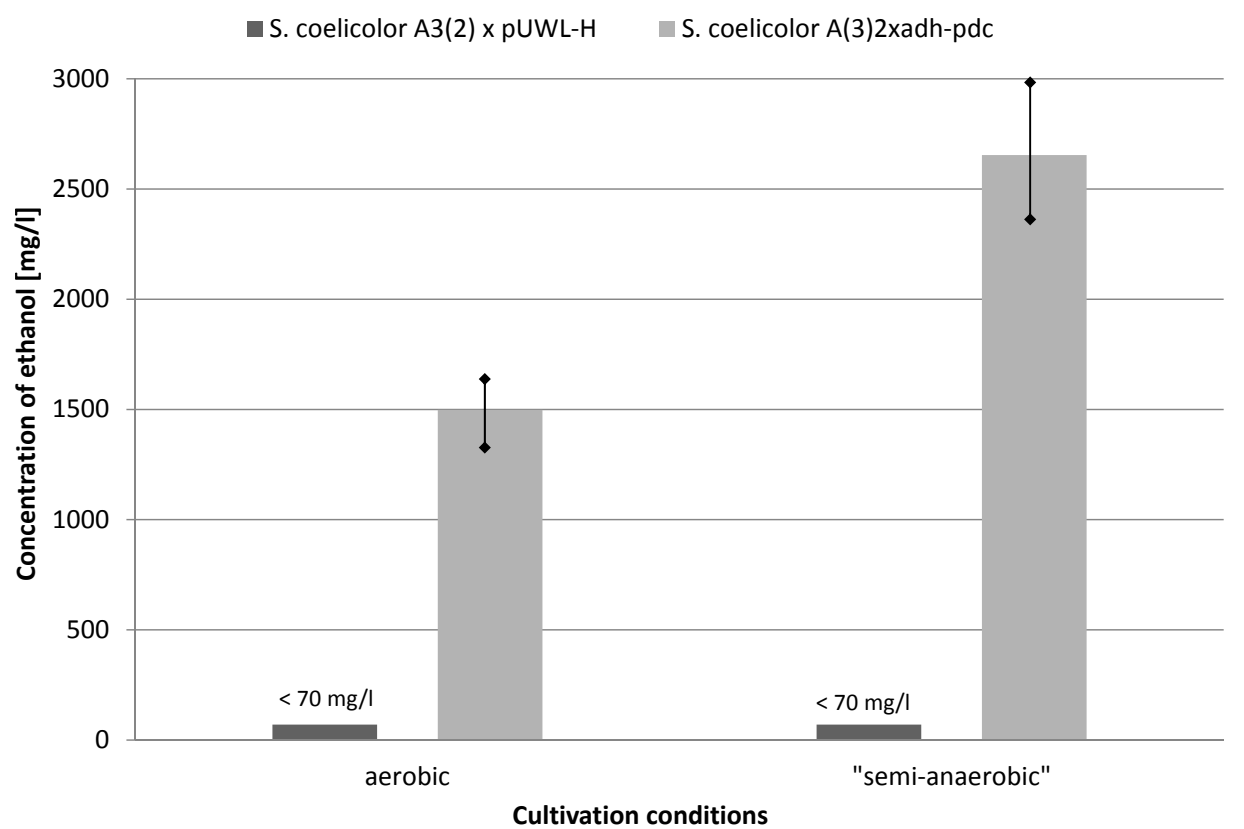

Fig. (1). Ethanol production of S. coelicolor A3(2) strains. Average amounts of ethanol produced in 10 individual experiments with S. coelicolor A3(2) x adhpdc and S. coelicolor A3(2) x pUWL-H (2) under aerobic conditions and under "semi-anaerobic" conditions, respectively. The minimal ethanol concentration detectable by our methods was $70 \mathrm{mg} / \mathrm{l}$. 
to $2.6 \mathrm{~g} / \mathrm{l}$. Results of this study show that Streptomyces strains are promising candidates for synthetic biology approaches. It is probable, that Streptomyces strains should be able to produce much more ethanol. We think that one very promising strategy is to knock out genes encoding for enzymes of competing pathways of pyruvate as well as acetylCoA metabolism in order to provide more of these important intermediates for the synthesis of ethanol. The genus of Streptomyces contains a huge variety of species providing great opportunities to find better fitted strains for the production of ethanol than S. coelicolor.

We could show that $S$. coelicolor tolerates ethanol concentrations in the medium up to $3 \%[\mathrm{~V} / \mathrm{V}]$, thus productions of $30 \mathrm{ml} / \mathrm{l}$ or $24 \mathrm{~g} / \mathrm{l}$, respectively, should be possible. Even if higher production levels could be achieved, ethanol could be removed from the media like frequently performed in current proceedings. Future work will indicate whether this proposal can be confirmed and these bacteria can be enhanced to feasible hosts for the production of biofuels.

\section{ACKNOWLEDGEMENT}

We thank Agnès Millet (University of Freiburg) for her support in GC/MS measurement. We also thank Andriy Luzhetskyy for helpful discussion.

\section{CONFLICT OF INTEREST}

None declared.

\section{REFERENCES}

[1] Drubin DA, Way JC, Silver PA. Designing biological systems. Genes Dev 2007; 21: 242-54.

[2] Lin Y, Tanaka S. Ethanol fermentation from biomass resources: current state and prospects. Appl Microbiol Biotechnol 2005; 69: 627-42.

[3] Tirado-Acevedo O, Chinn MS, Grunden AM. Production of biofuels from synthesis gas using microbial catalysts. Adv Appl Microbiol 2010; 70C: 57-92.

[4] Ingram LO, Conway T, Clark DP, Sewell GW, Preston JF. Genetic engineering of ethanol production in Escherichia coli. Appl Environ Microbiol 1987; 53: 2420-5.

[5] Du J, Shao Z, Zhao H. Engineering microbial factories for synthesis of value-added products. J Ind Microbiol Biotechnol 2011; 38: 873-90.

[6] Lynd LR, van Zyl WH, McBride JE, Laser M. Consolidated bioprocessing of cellulosic biomass: an update. Curr Opin Biotechnol 2005; 16: 577-83.

[7] Linger JG, Adney WS, Darzins A. Heterologous expression and extracellular secretion of cellulolytic enzymes by Zymomonas mobilis. Appl Environ Microbiol 2010; 76: 6360-9.

[8] Gao H, Zhuo Y, Ashforth E, Zhang L. Engineering of a genomereduced host: practical application of synthetic biology in the over- production of desired secondary metabolites. Protein Cell 2010; 1: 621-6.

[9] MacNeil DJ, Gewain KM, Ruby CL, Dezeny G, Gibbons PH, MacNeil T. Analysis of Streptomyces avermitilis genes required for avermectin biosynthesis utilizing a novel integration vector. Gene 1992; 111: 61-8.

[10] Sambrook J, Russell DW. Molecular cloning: A laboratory manual. $3^{\text {rd }}$ ed. New York: Cold Spring Harbor Laboratory Press 2001.

[11] Westrich L, Domann S, Faust B, Bedford D, Hopwood DA, Bechthold A. Cloning and characterization of a gene cluster from Streptomyces cyanogenus S136 probably involved in landomycin biosynthesis. FEMS Microbiol Lett 1999; 170: 381-7.

[12] Höltzel A, Jack RW, Nicholson GJ, et al. Streptocidins A-D, novel cyclic decapeptide antibiotics produced by S. sp. Tü 6071. II. Structure elucidation. J Antibiot (Tokyo) 2001; 54(5): 434-40.

[13] Drautz H, Zähner H, Rohr J, Zeeck A. Metabolic products of microorganisms. 234 Urdamycins, new angucycline antibiotics from S. fradiae. 1. Isolation, characterization and biological properties. J Antibiot (Tokyo) 1986; 39: 1657-69.

[14] Pospisil S. Resistance of Streptomyces cinnamonensis to butyrate and isobutyrate: production and properties of a new anti-isobutyrate (AIB) factor. J Gen Microbiol 1991; 137: 2141-6.

[15] Wallace KK, Zhao B, McArthur HAI, Reynolds KA. In vivo analysis of straight-chain and branched-chain fatty acid biosynthesis in three actinomycetes. FEMS Microbiol Lett 1995; 131: 227-34.

[16] Cane DE, Luo G, Khosla C, Kao CM, Katz L. Erythromycin biosynthesis. Highly efficient incorporation of polyketide chain elongation intermediates into 6-deoxyerythronolide B in an engineered Streptomyces host. J Antibiot (Tokyo) 1995; 48(7): 647-51.

[17] Kieser T, Bibb M, Buttner MJ, Chater KF, Hopwood DA. Practical Streptomyces Genetics. Norwich, UK: The John Innes Foundation 2000.

[18] Gomez-Escribano JP, Bibb MJ. Engineering S. coelicolor for heterologous expression of secondary metabolite gene clusters. Microb Biotechnol 2011; 4(2): 207-15.

[19] Petzke L. Transgenese in Streptomyceten: Transposons, Rekombinasen und Meganukleasen. PhD. Dissertation. Germany: University of Freiburg 2010.

[20] Bräu B, Sahm H. Cloning and expression of the structural gene for Pyruvate decarboxylase of Zymomonas. Arch Microbiol 1986; 144: 296- 301.

[21] Bentley SD, Chater KF, Cerdeño-Tárraga AM, et al. Complete genome sequence of the model actinomycete $S$. coelicolor A3(2). Nature 2002; 417: 141-7.

[22] Borodina I, Krabben P, Nielsen J. Genome-scale analysis of $S$. coelicolor A 3 (2) metabolism. Genome Res 2005; 15: 820-9.

[23] Calderone TL, Stevens RD, Oas TG. High-level misincorporation of lysine for arginine at AGA codons in a fusion protein expressed in Escherichia coli. J Mol Biol 1996; 262: 407-12.

[24] Kane JF. Effects of rare codon clusters on high-level expression of heterologous proteins in Escherichia coli. Curr Opin Biotechnol 1995; 6: 494-500.

[25] Berríos-Rivera SJ, Bennett GN, Sann KJ. Metabolic Engineering of Escherichia coli: Increase of NADH Availability by Overexpressing an NADP-Dependent Formate dehydrogenase. Metab Eng 2002; 4: 217-29.

[26] Nielsen DR, Leonard E, Yoon SH, Tseng HC, Yuan C, Prather KL. Engineering alternative butanol production platforms in heterologous bacteria. Metab Eng 2009; 11: 262-73. 